\title{
Self-reported oral health status and associated factors among Afghan refugees in Peshawar Pakistan; a pilot study
}

\author{
Syed Abdul Qadir ${ }^{1}$, Shahzad Muhammad², Maria Ishaq Khattak ${ }^{3}, Z_{\text {Zohaib Khan }}^{4}$, Muslim Khan ${ }^{5}$, Zia Ul Haq ${ }^{6}$
}

\author{
Submitted: \\ November 11, 2020 \\ Accepted: \\ December 16, 2020

\begin{abstract}
Author Information
${ }^{1,2}$ Khyber Medical University Institute

of Basic Medical Sciences

${ }^{3,6}$ Khyber Medical University Institute

of Public Health and Social Sciences

${ }^{4}$ Khyber Medical University Office of

Research Innovation and Commercialization

${ }^{5}$ Khyber College of Dentistry
\end{abstract}

\section{Corresponding Author}

Shahzad Muhammad

Khyber Medical University Institute

of Basic Medical Sciences

Email: shahzad.ibms@kmu.edu.pk

\begin{abstract}
Introduction: Afghan refugees in Pakistan is the third largest refugee community in the world. However, till date, information about their oral health and disease burden is very limited. The current is aimed to assess self-reported oral health status, practices, dental care access and associated factors among Afghan refugees in district Peshawar, Pakistan.

Material \& Methods: This pilot, cross sectional study was conducted on 644 adult Afghan refugees residing in district Peshawar from June to September 2020. Socio-demographic characteristics and data on selfreported oral health status, oral hygiene habits and dental care access was collected using self-reported oral health questionnaire. Statistical tests were applied to determine association between self-reported oral health status and participants characteristics using SPSS.

Results: Of all the respondents, majority (79.3\%) were Pashtun by ethnicity and $41.6 \%$ did not obtain any formal education. Nearly all (97.2\%) of them reported cleaning their teeth regularly, at least once a day with tooth brush and tooth paste being the commonest cleansing agents. More than half participants (58.1\%) rated their oral health good/very good and $68.0 \%$ were satisfied with their dental appearance. Tooth ache and sensitivity were the most commonly reported oral problems. $28.7 \%$ of the participants never visited dentist in their life. Most of the participants (82.6\%) felt need of dental care in the past one year but could not get it due to financial constraints. Significant association were found between self-rated oral health and age, marital status, country of birth, formal education and dentist visit $(\mathrm{p}<0.05)$.

Conclusion: Afghan refugees in Pakistan have poor self-reported oral health status. Access to dental care and oral health promotion and educations programs are crucial to improve oral health of this vulnerable population.
\end{abstract}

The authors declared no conflict of interest and agreed to be accountable for all aspects of the work in ensuring that questions related to the accuracy or integrity of any part of the work are appropriately investigated and resolved.All authors contributed substantially to the planning of research, questionnaire design, data collection, data analysis and write-up of the article.

This article may be cited as:Qadir SA, Muhammad S, Khattak MI, Khan Z, Khan M, Haq Z. Self-reported oral health status and associated factors among afghan refugees in Peshawar Pakistan; a pilot study. Reh J Health Sci. 2020;2(2). 40-45

\section{INTRODUCTION}

During the last decade, the world has witnessed the worst refugee crises of all time with the number of refugees increasing at a staggering rate. The United Nations High Commission for Refugees (UNHCR) estimates that there were at least 26 million refugees across the globe in the year 2019 with $68 \%$ belonging to just five countries including Syria, Venezuela, Afghanistan, South Sudan and Myanmar. ${ }^{1}$ Approximately $73 \%$ of the global refugee population is hosted in the neighboring countries. Despite its own deep rooted economic, geopolitical, poverty and social issues, ${ }^{2}$ Pakistan has given shelter to millions of Afghan refugees who fled to Pakistan in 1978 - 79 due to Soviet invasion of Afghanistan and U.S./NATO/ISAF-led invasion in 2001. Currently, Pakistan ranks third among the list of the countries hosting the largest number (1.4 million) of refugees. ${ }^{1}$

Refugees constitute a vulnerable population and these individual experience a series of traumatic events during their transit from home country and as a results, are at greater risk of poor physical, mental and social health. ${ }^{3}$ Compared to the local population in the host country, refugees generally have poor health and experience higher prevalence of certain communicable and noncommunicable diseases. ${ }^{4,5}$ Furthermore, some studies have reported poor oral health in the refugee population in different countries. ${ }^{6-8}$ Poor oral health not only affects an individual's ability to eat, drink, swallow and maintain esthetic appearance and nutrition; it is also inextricably linked to one's general health, wellbeing and quality of life. ${ }^{9}$ Although, the international community has recognized oral diseases as health priority for refugees and asylum seekers, ${ }^{10}$ till date, no uniform policy exist due to the lack of research evidence in the local contexts to inform decision makers and dental practitioners about oral healthcare needs and access in refugee populations. ${ }^{11}$ Majority of the evidence exist so far has come from developed countries of the world. It is, therefore, essential to understand the oral healthcare needs and access to dental care in refugee populations residing in developing countries using cost effective and reliable approaches. Self-reported oral health is a simple, comprehensive, easy to use and reliable measure of oral health status. Compared to clinical examination, data collection through self-reported information has the advantage of being easier and cost and time effective particularly in population-based studies. Self-reported data not only provide an assessment of perceived oral health status, satisfaction, health seeking behavior and use of dental services; it is also strongly associated with clinical findings, ${ }^{12}$ un-met treatment needs in population ${ }^{13}$ and individual health seeking behavior. ${ }^{14}$ It has been widely used to assess oral health status and dental services utilization in different refugee populations across the 
world. ${ }^{8,15-18}$ Although a few studies have focused on the general health and disease status of Afghan refugees population in Pakistan, ${ }^{2,19,20}$ to the best of our knowledge, there is no documented study on their oral health status.

The aim of the present study was to assess self-reported oral health status, oral hygiene practices and access to dental care of Afghan refugees currently residing in Peshawar, Pakistan.

\section{MATERIALS \& METHODS}

This cross-sectional study was conducted at district Peshawar which is the capital city of Khyber Pakhtunkhwa province of Pakistan. The duration of the study was from June to September 2020. The sample size $(n=644)$ was calculated using the formula "n= [DEFF*Np(1-p)]/ [(d2/Z21- $\left./ 2^{*}(\mathrm{~N}-1)+\mathrm{p}^{*}(1-\mathrm{p})\right]$ " in Epi Info.

${ }^{21}$ We used a population size $(\mathrm{N}): 1000000$, a hypothesized $\%$ frequency of difficulty in access to dental care in the population (p): $72 \%+/-5$ based on the findings of a study in a socially disadvantaged group in Pakistan, ${ }^{22}$ confidence limits as \% of 100 (absolute +/- \%) (d): 5\%, and a design effect (for respondent driven surveys-DEFF):2. ${ }^{23}$ We employed a Non-probability respondent driven sampling wherein participants who met the inclusion criteria were recruited until the required sample size was achieved. Participants were included in the study if they were adult Afghan refugees (both male and female) aged $18-60$ and resided in the designated refugee villages or settled areas within district Peshawar for at least one year. Those with chronic illness or deemed mentally unfit to give informed consent were excluded from the study. An information sheet translated into the local language (Pashto and Dari) was provided to all the participants and informed verbal consent was obtained before data collection. Those who were unable to read, contents of the participant information sheet and consent were read loudly and the questionnaire was filled by the data collectors for their convenience and transparency. The study was approved from ethics review board of Khyber Medical University, Peshawar. Data was collected by five trained data collectors using selfreported oral health questionnaire. Before implementation, the questionnaire was translated and contents validated by 3 professional dentists and a medical education expert followed by pre-testing on 20 participants. The final questionnaire had 21 open-ended and multiple-choice questions in four sections. Section A included seven questions about sociodemographic characteristics of the participants such as age, gender, ethnicity and household monthly income. Section B included 5 questions about participant's oral hygiene practice and behaviors. Sections $\mathrm{C}$ included four questions related to self-oral health condition and satisfaction of the participants. Section D contained five questions on access to dental care and the reasons for taking/not taking dental care.

Data from hard copies of the questionnaires was entered into SPSS version 22. For categorical data we calculated frequencies and percentages, while means and standard deviations were computed for numerical data. To assess the association between self-reported oral health participant's characteristics, some of the variables (age, education) were dichotomized before applying Chi-Squared tests. A p-value of less than 0.05 was considered significant.

\section{RESULTS}

Data was collected from 644 Afghani refugees adults of which, 319 (49.5\%) were male and 325 (50.5\%) were females. Mean age of the participants was $30.32 \pm 9.34$ years. Around $76 \%$ of the participants were born in Pakistan and were Pashtun by ethnicity. Concerning education, $41.6 \%$ of the participants did not obtain any formal education, $28.7 \%$ had primary level education ( $1-5$ years), $21.9 \%$ had high school or college level education (6 - 12 years) and only $6.4 \%$ had at least one year in university. Average monthly household income was 22810 in Pakistani rupees. Detailed sociodemographic characteristics of the participants are summarized in Table 1.
Table 1: Basic demographic characteristics of the participants $(\mathrm{n}=644)$

\begin{tabular}{|c|c|c|}
\hline Characteristics & & $\mathrm{n}(\%)$ \\
\hline \multirow{2}{*}{ Gender } & Male & $319(49.5)$ \\
\hline & Female & $325(50.5)$ \\
\hline \multirow{3}{*}{ Age } & 18 - 34 Years & $440(68.3)$ \\
\hline & $35-49$ Years & $170(26.4)$ \\
\hline & 50 - 60 Years & $34(5.3)$ \\
\hline \multirow{3}{*}{ Marital Status } & Single & $118(18.3)$ \\
\hline & Married & $517(80.3)$ \\
\hline & Widowed & $9(1.4)$ \\
\hline \multirow{2}{*}{ Country of Birth } & Afghanistan & $493(76.6)$ \\
\hline & Pakistan & $151(23.4)$ \\
\hline \multirow{4}{*}{ Ethnicity } & Pashtun & $489(75.9)$ \\
\hline & Hazara & $42(6.5)$ \\
\hline & Uzbek & $93(14.4)$ \\
\hline & Others & $20(3.1)$ \\
\hline \multirow{4}{*}{ Education } & $\begin{array}{l}\text { No formal } \\
\text { Education }\end{array}$ & $277(43.0)$ \\
\hline & Primary level & $185(28.7)$ \\
\hline & $\begin{array}{l}\text { High school \& } \\
\text { College level }\end{array}$ & 141 (21.9). \\
\hline & University level & $41(6.4)$ \\
\hline \multirow{3}{*}{ Monthly household income } & Rs. $\leq 20,000$ & $366(57.0)$ \\
\hline & Rs. $21,000-50,000$ & $88(13.5)$ \\
\hline & Rs. $>50,000$ & $49(7.6)$ \\
\hline
\end{tabular}

When asked about the oral hygiene practices (Table 2), $97.2 \%$ of the participants reported that they clean their teeth regularly at least once $(49 \%)$ or twice $(31.1 \%)$ a day, mostly $(80.1 \%)$ in the morning time. Tooth brush and tooth paste was the most common method for teeth cleaning used by 355 (55.1\%) participants followed by Miswak (Chewing stick) and Dandasa (Walnut Tree Bark/ Juglan regia) used by 201 (31.2\%) and 120 (18.6\%) participants respectively. Dental flossing was least common and reported by only $14(2.2 \%)$ participants. 
Table 2: Oral hygiene habits of the participants

\begin{tabular}{lll}
\hline \multicolumn{1}{c}{ Characteristics } & $\mathrm{n}(\%)$ \\
\hline $\begin{array}{l}\text { Do you clean your teeth } \\
\text { regularly? }\end{array}$ & Yes & $626(97.2)$ \\
& No & $18(2.8)$ \\
& Tooth Brush & $355(55.2)$ \\
& Miswak & $201(31.4)$ \\
$\begin{array}{l}\text { What do you use to clean } \\
\text { your teeth? }\end{array}$ & Dandasa & $120(18.9)$ \\
& Dental Floss & $14(2.2)$ \\
& Other & $17(2.7)$ \\
$\begin{array}{l}\text { How many times do you } \\
\text { clean your teeth every day? }\end{array}$ & 2 times & $304(49)$ \\
& $\geq 3$ times & $193(31.1)$ \\
& Morning & $514(80.4)$ \\
$\begin{array}{l}\text { What time do you clean } \\
\text { your teeth? }\end{array}$ & $\begin{array}{l}\text { Afternoon } \\
\text { Before going } \\
\text { to bed } \\
\text { Other }\end{array}$ & $220(34.4)$ \\
& $330(51.6)$ & $35(5.5)$
\end{tabular}

Of all the participants, 374 (58.1\%) participants rated their oral health as good/very good and 438 (68.0\%) were satisfied the appearance of their teeth (Table 3).

Table 3: Self-reported oral health status

\begin{tabular}{|c|c|c|}
\hline Variables & & n (\%) \\
\hline \multirow{2}{*}{$\begin{array}{l}\text { How would you describe } \\
\text { your oral health (mouth, } \\
\text { teeth and gums) at present? }\end{array}$} & Fair/Poor & $270(41.9)$ \\
\hline & Good/very good & $374(58.1)$ \\
\hline \multirow{3}{*}{$\begin{array}{l}\text { Compared to other people, } \\
\text { how would you describe } \\
\text { your general health at present? }\end{array}$} & Fair/Poor & $218(33.9)$ \\
\hline & Good/very good & $426(66.1)$ \\
\hline & Yes & $438(68.0)$ \\
\hline \multirow[t]{4}{*}{$\begin{array}{l}\text { Are you satisfied with the } \\
\text { appearance of your teeth? }\end{array}$} & No & $174(27.0)$ \\
\hline & Don't Know & $32(5.0)$ \\
\hline & Tooth ache & \\
\hline & Yes & $349(54.2)$ \\
\hline \multirow{4}{*}{$\begin{array}{l}\text { Currently or in the past } 12 \\
\text { month, have you experienced } \\
\text { any of the following condition? }\end{array}$} & No & $295(45.8)$ \\
\hline & \multicolumn{2}{|l|}{ Sensitivity in Tooth } \\
\hline & Yes & $361(56.1)$ \\
\hline & No & $283(43.9)$ \\
\hline
\end{tabular}

Gum Bleeding

Yes
No
Bad Breath
Yes
No

$307(47.7)$

$337(52.3)$

$434(67.4)$

Each participant was also asked whether currently or in the past one year, they had experienced any of the four specific oral health problems (tooth pain, sensitivity, gum bleeding or bad breath). The most common oral problem was sensitive teeth (56.1) and dental pain (54.2\%). Gum bleeding and bad breath were also common. In terms of dental care access, only 18 (2.8\%) participants reported seeing a dentist regularly every $6-8$ months while over half $(54.3 \%)$ of them visit dentist only when they have dental pain. Furthermore, 183 (28.7\%) participants have never been to a dentist in their life. The participants were further asked about when they last visited a dentist and the reason of visit. Majority (47.1\%) of the participants reported visiting dentist in the last 6 months and citing dental pain as their main reason for their visit to dentist reported by 359 (77.5\%) participants. $82.6 \%$ of the respondent's reports need of dental care in the past one year but could not receive due expensiveness (65\%) (Table 4 ).

Table 4: Dental care access and utilization

\begin{tabular}{|c|c|c|}
\hline Variables & & n $(\%)$ \\
\hline \multirow{4}{*}{$\begin{array}{l}\text { How often do you } \\
\text { visit dentist? }\end{array}$} & Regularly (Every 6 - 8 months) & $18(2.8)$ \\
\hline & Occasionally & $90(14.1)$ \\
\hline & When I have dental pain & $346(54.3)$ \\
\hline & I never visited dentist & $183(28.7)$ \\
\hline \multirow{3}{*}{$\begin{array}{l}\text { When did you last } \\
\text { visited your dentist? }\end{array}$} & Last six months & $217(47.1)$ \\
\hline & Last one year & $117(25.4)$ \\
\hline & more than a year & $127(27.5)$ \\
\hline \multirow{4}{*}{$\begin{array}{l}\text { What was the reason } \\
\text { for your last visit to } \\
\text { the dentist? }\end{array}$} & Dental pain & $359(77.5)$ \\
\hline & Bleeding gums & $12(2.6)$ \\
\hline & On someone advice & $32(6.9)$ \\
\hline & Other & $60(13.0)$ \\
\hline \multirow{3}{*}{$\begin{array}{l}\text { Dental care was needed } \\
\text { in the past } 12 \text { months } \\
\text { but couldn't get it. }\end{array}$} & No & $28(6.0)$ \\
\hline & Yes & $384(82.6)$ \\
\hline & Don't know & $53(11.4)$ \\
\hline \multirow{2}{*}{$\begin{array}{l}\text { Reasons for not } \\
\text { taking dental care? }\end{array}$} & Can't afford & $163(35.0)$ \\
\hline & Dental care is expensive & $303(65.0)$ \\
\hline
\end{tabular}


The association between self-rated oral health (good/very good vs fair/poor) and participant's characteristics is presented in Table 5. Significant association was found between self-rated oral health and age, marital status, country of birth, formal education and dentist visit.

Table 5: Association between self-rated oral health and participants characteristics

\begin{tabular}{|c|c|c|c|c|}
\hline \multirow[b]{3}{*}{ Respondents characteristics } & & \multicolumn{2}{|c|}{ Self-rated oral health } & \multirow[b]{3}{*}{ Significance } \\
\hline & & Good/very & & \\
\hline & & Good & Fair/Poor & \\
\hline \multirow{2}{*}{ Age } & 29 Years and below & $241(71.9)$ & $94(28.1)$ & $<0.005$ \\
\hline & Above 29 years & $133(43.0)$ & $176(57)$ & \\
\hline \multirow{3}{*}{ Gender } & male & $195(61.1)$ & $124(38.9)$ & 0.129 \\
\hline & female & $179(55.1)$ & $146(44.9)$ & \\
\hline & Single & $85(72.0)$ & $33(28.0)$ & $<0.005$ \\
\hline \multirow[t]{2}{*}{ Marital Status } & Married & $280(54.2)$ & $237(45.8)$ & \\
\hline & Widowed & $9(100)$ & $0(0)$ & \\
\hline \multirow{3}{*}{ Country of Birth } & Pakistan & 305 (61.9) & $188(38.1)$ & $<0.005$ \\
\hline & Afghanistan & $69(45.7)$ & $82(54.3)$ & \\
\hline & Pashtun & $282(57.7)$ & $207(42.3)$ & 0.963 \\
\hline \multirow{3}{*}{ Ethnicity } & Hazara & $24(57.1)$ & $18(42.9)$ & \\
\hline & Uzbek & $55(59.1)$ & $38(40.9)$ & \\
\hline & Others & $13(65.0)$ & $7(35)$ & \\
\hline \multirow[t]{2}{*}{ Formal Education } & No & $141(50.9)$ & $136(49.1)$ & $<0.01$ \\
\hline & Yes & $233(63.5)$ & $134(36.5)$ & \\
\hline \multirow{3}{*}{$\begin{array}{l}\text { Monthly household income } \\
\text { categories }\end{array}$} & $\leq 20,000 \mathrm{PKR}$ & $277(56.5)$ & $213(43.5)$ & 0.339 \\
\hline & 21,000 - 50,000 PKR & $58(61.1)$ & $37(38.9)$ & \\
\hline & $>50,000 \mathrm{PKR}$ & $35(64.8)$ & $19(35.2)$ & \\
\hline \multirow{2}{*}{$\begin{array}{l}\text { How many times do you } \\
\text { clean your teeth every day? }\end{array}$} & One time & $180(59.2)$ & $124(40.8)$ & 0.365 \\
\hline & Two or more than two times & $190(60.1)$ & $126(39.9)$ & \\
\hline \multirow[t]{4}{*}{$\begin{array}{l}\text { How often do you visit } \\
\text { dentist? }\end{array}$} & $\begin{array}{l}\text { Regularly (Every } 6 \text { - } 8 \\
\text { months) }\end{array}$ & $18(100)$ & $0(0)$ & $<0.05$ \\
\hline & Occasionally & $79(87.7)$ & $11(12.2)$ & \\
\hline & When I have dental pain & $129(37.3)$ & $217(62.7)$ & \\
\hline & I never visited dentist & $143(78.1)$ & $40(21.9)$ & \\
\hline
\end{tabular}




\section{DISCUSSION}

Afghan refugees in Pakistan is one of the world largest protracted refugee community. Due to historic and cultural ties with Afghanistan, the city is host to largest number of Afghan refugees in the country. They live either in designated Afghan Refugee Villages (ARV) or in the settled areas of the city thereby offering an excellent opportunity to assess oral health problem of a multiethnic Afghan population with varying socioeconomic and education backgrounds. The present study, to the best of our knowledge, is the first comprehensive report on self-reported oral health status, practices and dental care access in Afghan refugees residing in Peshawar, the city hosting the largest number of refugees in Pakistan. In the current study, while $97.2 \%$ of the participants reported good oral hygiene practices by cleaning their teeth at least once a day; the use of dental floss use and regular visit to dentist was very low. In fact, majority of them visit dentist only when they experience dental pain. Overall, the oral hygiene practices do not match the standard requirement of maintaining good oral hygiene i.e. brushing teeth at least twice a day (morning and night) preferably with a fluoridated toothpaste, use of dental floss and regular visit to dentist. ${ }^{24}$ These findings are not unusual since other studies from developing countries suggest that refugees tend to postpone seeking dental treatment until there is pain. ${ }^{25} \mathrm{It}$ is well established that untreated dental pain typically is a risk factor for general health and can initiate infections in other anatomical sites. Poor socioeconomic status, adverse living conditions especially in refugee villages and low education level might be the possible reasons for the gap in oral hygiene practices. It is, therefore, important to launch oral health education and awareness campaigns to educate and motivate refugee population about the importance of brushing teeth at least twice a day with a fluoridated toothpaste, cleaning of interdental spaces using dental floss and regular dental checkups even in the absence of dental pain or other acute complaint. An interesting finding of the study was the use of Dandasa; a peel product from the walnut tree as cleansing agent by $37.3 \%$ of the female participants. Dandasa has traditionally been used as teeth whitening agent in Afghanistan, Iran, Egypt and Pashtun dominant areas of Pakistan. With time, Dandasa is losing its popularity among the population. However, its use still common particularly in rural areas of Khyber Pakhtunkhwa where it is still used as teeth cleansing and whitening agent ${ }^{27}$.

In the current study, more than half of the participants rated their oral health as good/very good. These findings are in concordance with the previous studies conducted in immigrants and refugee population in Finland and USA. ${ }^{16,17}$ However, it should be noted that perception regarding oral health is a complex process through which an individual makes relations to the state of their health and daily life experiences based on the information and knowledge available to them about their health. ${ }^{28}$ Self-reported oral health is also a subjective phenomenon and past encounters of sociocultural and historical circumstances of each individual also play an important role. ${ }^{29}$ That's why, majority of the participants experienced one or more oral health problem (sensitivity, tooth ache, gum bleeding, bad breath) in the past one year despite perceiving their oral health as good/very good. Moreover, an overwhelming majority ( $82.6 \%$ ) of the participants felt that they needed dental treatment in the past one year but couldn't get it due to financial constraints. Undoubtedly, immigrants and refugees have limited access to dental care even in many developed countries. ${ }^{30}$ There could be several possible reasons including socioeconomic status, lack of inclusivity in health care system and cultural and language barriers. ${ }^{6,16,30}$ However, it's not only refugees but even Pakistani citizens themselves face disparity in accessing health care especially in the rural areas of the country. ${ }^{2}$ In addition, Pakistan and other low and middle-income countries neglect dental health such as oral health promotion, oral health screening, restorative treatment, and referral services at primary health care level. ${ }^{31}$

Our final findings is regarding significant association found between self-rated oral health and age, marital status, country of birth, formal education and dentist visit is in line with the literature. These findings are consistent with Finlayson et al study ${ }^{32}$ that report self-rated oral health (whether good or poor) being associated with age, relationship status, country of origin and visiting the dentist. Another way to explain this significant association amongst refugee communities may be acculturation which is known to have enormous influence on the oral health status (examined and self-rated), practices and access to dental care. $^{33}$

This study provides useful insight about the oral health practices, self-reported oral health status and access to oral health services of Afghan refugees living in Peshawar, Khyber Pakhtunkhwa. The study identifies barriers to accessing oral health care and oral hygiene practices towards which oral health promotion programmes can be directed. The study gained information through individual interviews which lasted for about 20 minutes, making the data collection time-consuming. Yet, personal interviews are known to increase the importance of a study. The study design required that participants were given sufficient time to understand the questions asked and respond appropriately. Another strength of this study is that all questions were asked in the local language 'Pashto' in order to remove ambiguity of language issues.

There are a few limitations of this study. First, dental examination of participants is essential in order to determine their oral health status. However, due to time and resource constraints data, through direct clinical examinations of participants was not conducted. Secondly, questions can be raised about the generalizability of the study due to the sample size of this study. However, previous research suggests that for studies using interviews it is satisfactory to limit their participants. Third, a potential bias in the study by choosing convenience sampling instead of cluster sampling. Finally, the study questionnaire does not include questions regarding diet and sugar intake, smoking habits which could also impact oral health status. All these limitations should be addressed in future studies.

\section{CONCLUSION}

In summary, the present study shows poor oral health status and dental care access among Afghan refugees in Pakistan. It further suggests that socio-demographic characteristics (age, marital status, country of birth, education) as well as dental care access is associated with self-reported oral health. It is crucial to emphasize on dental care access and health promotion and education programs to improve oral health status of this vulnerable population. 


\section{REFERENCES}

1. UNHCR. UNHCR - Refugee Statistics [Internet]. UNHCR. 2019 [cited 2020 Jul 6]. Available from:

https://www.unhcr.org/refugee-statistics/

2. Malik MS, Afzal M, Farid A, Khan FU, Mirza B, Waheed MT. Disease Status of Afghan Refugees and Migrants in Pakistan. Front Public Health. 2019;7:185.

3. Langlois EV, Haines A, Tomson G, Ghaffar A. Refugees: towards better access to health-care services. Lancet Lond Engl. 2016 Jan 23;387(10016):319-21.

4. Janda A, Eder K, Fressle R, Geweniger A, Diffloth N, Heeg M, et al. Comprehensive infectious disease screening in a cohort of unaccompanied refugee minors in Germany from 2016 to 2017: A crosssectional study. PLOS Med. 2020 Mar 31;17(3):e1003076

5. Jervelund SS, Nordheim O, Stathopoulou T, Eikemo TA. Non-communicable Diseases among Refugee Claimants in Greek Refugee Camps: Are Their Health-care Needs Met? J Refug Stud. 2019 Dec 28;32(Special_Issue_1):i36-51.

6. Roucka TM. Access to dental care in two long-term refugee camps in western Tanzania; programme development and assessment. Int Dent J. 2011 Apr;61(2):109-15.

7. Cote $S$, Geltman P, Nunn M, Lituri K, Henshaw M, Garcia RI. Dental Caries of Refugee Children Compared With US Children. Pediatrics. 2004 Dec 1;114(6):e733-40.

8. Ghiabi E, Matthews DC, Brillant MS. The oral health status of recent immigrants and refugees in Nova Scotia, Canada. J Immigr Minor Health. 2014 Feb;16(1):95-101.

9. Kalache A, Gatti A. Active ageing: a policy framework. Adv Gerontol Uspekhi Gerontol. 2003;11:7-18.

10. UNHCR. Refworld I UNHCR Resettlement Handbook, 2011 [Internet]. Refworld. 2012 [cited 2020 Sep 23]. Available from: https://www.refworld.org/docid/4ecb973c2 .html

11. Riggs E, Gibbs L, Kilpatrick N, Gussy M, van Gemert C, Ali S, et al. Breaking down the barriers: a qualitative study to understand child oral health in refugee and migrant communities in Australia. Ethn Health. 2015;20(3):241-57.

12. Chen $X$, Naorungroj $S$, Douglas $C E$, Beck JD. Self-reported Oral Health and Oral Health Behaviors in Older Adults in the Last Year of Life. J Gerontol Ser A. 2013 Mar 22;68(10):1310-5.

13. Locker D, Clarke M, Payne B. Self-perceived oral health status, psychological wellbeing, and life satisfaction in an older adult population. J Dent Res. 2000 Apr;79(4):970-5.
14. Gilbert GH, Shelton BJ, Chavers LS, Bradford EH. The paradox of dental need in a population-based study of dentate adults. Med Care. 2003 Jan;41(1):119-34.

15. Knighton R, Pinzon L, Singh T. Knowledge, Attitudes, Self-reported Oral Health Status in the Refugee Population in Utah. In American Public Health Association; 2019 [cited 2020 Jul 7]. Available from: https://apha.confex.com/apha/2019/meetin gapp.cgi/Paper/439109

16. Mattila A, Ghaderi $P$, Tervonen L, Niskanen L, Pesonen P, Anttonen V, et al. Selfreported oral health and use of denta services among asylum seekers and immigrants in Finland-a pilot study. Eur $\mathrm{J}$ Public Health. 2016 Aug 18;26(6):1006-10.

17. Okunseri C, Hodges J, Born D. Self-reported oral health perceptions of Somali adults in Minnesota: a pilot study. Int J Dent Hyg 2008 Jun 1;6:114-8.

18. Saadeh R, Cappelli D, Bober-Moken I, Cothron A, de la Torre M. Assessing Oral Health Status, Practices, and Access to Care among War-Affected Refugees Living in San Antonio, Texas. Eur J Dent [Internet]. $2020 \mathrm{May}$; Available from http://europepmc.org/abstract/MED/32447 752

19. Awan HR, Ihsan T. Prevalence of visual impairment and eye diseases in Afghan refugees in Pakistan. EMHJ - East Mediterr Health J 4 3 560-566 1998 [Internet]. 1998; $A v a i l a b \mid e \quad f r o m$ https://apps.who.int/iris/handle/10665/118 474

20. Suleman M. Malaria in Afghan refugees in Pakistan. Trans R Soc Trop Med Hyg. 1988 Jan 1;82(1):44-7.

21. CDC. Epi InfoTM [Internet]. 2019 [cited 2020 D e c 2 ]. A v a i I a b I e from : https://www.cdc.gov/epiinfo/index.html

22. Hemani A, Rauf F, Noori M, Faisal A. Barriers to the access of oral health care in individuals from lower socioeconomic communities in Karachi. J Liaquat Univ Med Health Sci. 2017 Oct 1;16:218-21.

23. Leon L, Des Jarlais D, Jauffret-Roustide M, Le Strat $Y$. Update on respondent-driven sampling: Theory and practical considerations for studies of persons who inject drugs. Methodol Innov. 2016 Oct 13;9. 1-9

24. Oral Health Tips | Adult Oral Health | Basics | Oral Health I CDC [Internet]. 2019 [cited 2020 Sep 23]. Available from https://www.cdc.gov/oralhealth/basics/ad ult-oral-health/tips.html

25. Lamb CEF, Whelan AK, Michaels C. Refugees and oral health: lessons learned from stories of Hazara refugees. Aust Health Rev Publ Aust Hosp Assoc. 2009 Nov;33(4):618-27.
26. Petersen PE. The World Oral Health Report 2003: continuous improvement of oral health in the 21st century--the approach of the WHO Global Oral Health Programme. Community Dent Oral Epidemiol. 2003 Dec;31 Suppl 1:3-23.

27. Syed $A Q$, Shahzad M, Yasar MY. Assessment of oral health related knowledge, attitude, and self-reported practices of families residing in Peshawar, Pakistan. Adv Basic Med Sci. 2019;3(1):54-8.

28. Martins AME de BL, Barreto SM, Pordeus IA Objective and subjective factors related to self-rated oral health among the elderly. Cad Saúde Pública. 2009 Feb;25(2):421-35.

29. Helman C. Culture, Health and IIIness, Fifth edition. CRC Press; 2007.630 p.

30. Keboa MT, Hiles N, Macdonald ME. The oral health of refugees and asylum seekers: a scoping review. Glob Health. 2016 Oct 7;12(1):59.

31. Basharat S, Shaikh BT. Primary oral health care: a missing link in public health in Pakistan. East Mediterr Health J. 2016;22(9):703-6.

32. Finlayson TL, Williams DR, Siefert $K$, Jackson JS, Nowjack-Raymer R. Oral Health Disparities and Psychosocial Correlates of Self-Rated Oral Health in the National Survey of American Life. Am J Public Health. 2010 Apr;100(Suppl 1):S246-55.

33. Gao X-L, McGrath C. A review on the oral health impacts of acculturation. J Immigr Minor Health. 2011 Apr;13(2):202-13. 